\title{
Integrated grey relational analysis and multi objective grey linear programming for sustainable electricity generation planning
}

\author{
Hanif Malekpoor ${ }^{1} \cdot$ Konstantinos Chalvatzis $^{1} \cdot$ Nishikant Mishra $^{2}$. \\ Mukesh Kumar Mehlawat ${ }^{3}$ • Dimitrios Zafirakis ${ }^{1}$ • Malin Song ${ }^{4}$
}

Published online: 30 June 2017

(C) The Author(s) 2017. This article is an open access publication

\begin{abstract}
Sustainable energy generation is a key feature in sustainable development and among various sources of energy electricity due to some unique characteristics seems particularly important. Optimising electricity generation mix is a highly complex task and requires consideration of numerous conflicting criteria. To deal with uncertainty of experts' opinions, inaccuracy of the available data and including more factors, some of which are difficult to quantify, in particular for environmental and social criteria, we applied grey relational analysis (GRA) with grey linguistic, and grey interval values to obtain the rank of each system. Then the obtained ranking were used as coefficients for a multi objective decision making problem, aimed to minimize the cost, import dependencies and emissions as well as maximizing the share of generation sources with better ranking. Due to existence of interval variables multi objective grey linear programming (MOGLP) method was used to solve the problem. Our results for the UK as a case study suggest increased role for all low carbon energy technologies and sharp reduction in the use of coal and oil. We argue that the integrated GRA-MOGLP approach provides an effective tool for the evaluation and optimisation of complex sustainable electricity generation planning. It is particularly promising in dealing with uncertainty and imprecisions, which reflect real-life scenarios in planning processes.
\end{abstract}

Keywords Electricity generation - Sustainable planning · MODM · Interval linear programming · GRA · MOGLP

Nishikant Mishra

mishra09@gmail.com

1 Norwich Business School, University of East Anglia, Norwich, UK

2 Hull University Business School, University of Hull, Hull, UK

3 Department of Operational Research, University of Delhi, New Delhi, Delhi, India

4 Anhui University of Finance and Economics, Bengbu 233030, China 


\section{Introduction}

Uninterrupted access to energy resources is a defining factor of modern economies. Arguably energy's role in economic systems is even greater than that of other resources and commodities simply because of the essential role of energy for the production, transformation and market delivery of all commodities and goods. Among energy resources, electricity is particularly important mainly for two reasons (Armaroli and Balzani 2011); firstly, because it can potentially substitute all other fuels in the transport, buildings and industrial sectors, and secondly because it can be generated without significant environmental emissions (Balat 2006; Kalkuhl et al. 2012). Moreover, electricity is a secondary form of energy which can be produced by a variety of fossil fuels and renewable energy sources, making use of a wide range of resource combinations depending on regional availability (Chalvatzis 2009).

Despite the aforementioned flexible characteristics, electricity is confronted with substantial challenges, such as increasingly stricter environmental constraints (Chalvatzis and Rubel 2015), social acceptability and support mechanisms of new forms of energy production facilities (Zafirakis et al. 2013), the lack of low cost storage in the electricity supply chain and the variability of renewable energy production. Within this context, power production systems have to comply with a complex set of regulations in addition to technical and societal constraints. Complexity in the power sector is arguably exacerbated with the introduction of new technologies such as distributed renewable energy generation, energy storage and electric private vehicles (Hofmann et al. 2016). This leads to an enormous growth in the number of market participants and the gradual transition from the large scale utility model and even the variability and alternation of consumer and producer roles as is possible for electric vehicles and households to both buy electricity and sell it back to the grid (Sioshansi 2012).

While complexity in decision making for power sector planning is inherently growing the literature offers a number of potential approaches. Linares and Romero (2000) used multi objective linear optimization, considering electricity derived costs and emissions minimization as their two objective functions, tried to find an optimal solution for electricity planning in Spain. Koroneos et al. (2004) generated a number of efficient solutions for the energy supply system of the island of Lesbos (Greece) by applying MODM linear optimization and concluded that renewable systems are adequate to produce optimal electricity power for this island. Unsihuay-Vila et al. (2011) proposed a Multi-Objective model for long-term expansion planning of electricity generation and transmission by considering sustainable energy development criteria. The proposed model is a well detailed mixed-integer linear model however all variables are considered as crisp valued and when it comes to sustainability, only environmental criteria have been considered. A Bi-Objective Linear Programming model was presented by Arnette and Zobel (2012) which determined the optimal mix of renewable energy sources and existing fossil fuel facilities on a regional basis, based on minimizing the cost and $\mathrm{CO}_{2}$ emissions as its objective functions. Perera et al. (2013) Combined MCDM and Multi-Objective Optimization to optimize a hybrid energy system for a standalone grid by considering levelized energy cost, unmet load fraction, wasted renewable energy and fuel consumption as objective functions. They applied TOPSIS to evaluate the solutions obtained in Pareto optimal front. Although applying TOPSIS for comparison in case of abundant solutions can be tiresome and inaccurate. Similarly, Promjiraprawat and Limmeechokchai (2013) presented a hybrid framework of multi-objective optimization and multi-criteria decision making to solve power generation expansion planning problems in Thailand. They first applied multi objective genetic algorithm to produce several solutions to the problem and then through Analytic Hierarchy Process (AHP) ranked the created optimized solutions. Purwanto 
et al. (2015) developed a bi-objective linear programming model which by minimizing the cost of production and $\mathrm{CO}_{2}$ emission to compute the share of renewable energy resources from generation mix in 2050 in Indonesia. In addition they have considered the technology diffusion in their model and compared the share of renewables with and without technology diffusion considerations. Sithole et al. (2016) by using an excel-based "Energy Optimisation Calculator" and utilizing assumptions about renewable share of generation and $\mathrm{CO}_{2}$ emissions restrictions required by UK government, obtained a least-cost solution for generation mix. In order to deal with uncertainty they conducted a sensitivity analysis and considering a $\pm 30 \%$ margin for fuel costs factor. However there are various factors in a mixed generation model that should be considered and analysis the combinations of these factors through sensitivity analysis is a hard task and a comprehensive analysis is difficult to reach.

The main shortcoming in the aforementioned approaches is not to consider the uncertainty of different factors and applying fixed and crisp values for all the factors in the model. However, many system parameters such as costs associated with operation and maintenance, capital costs, fuel consumption, production efficiency, demand prediction and greenhouse gases emitted by various generation systems, as well as systems' performance with respect to environmental and social criteria may appear uncertain and need to be presented by fuzzy or interval formats such as grey interval numbers. These uncertainties can have a significant effect over the optimization results and the decision makers' plans based on the obtained results (Cai et al. 2007). Interval Linear programming (ILP) (also named as grey linear programming) developed by Huang et al. (1992) is a technique to deal with situations where we have interval values due to existence of inexact values, error measurements or performing sensitivity analysis (Hlad1 2013). Interval linear programming since then has been developed into more complete and precise models and has proven its efficiency in solving problems in different fields.

Huang et al. (1995) further developed the interval linear programming by considering existence of interval variables and proposed a Grey Interval Linear Programming model solved through an interactive algorithm which can facilitate researchers to deal with discrete variables in allocation problems. While the most of the ILP applications have been in the field of environmental management and allocation of water supply sources (Cheng et al. 2003; Zhou et al. 2008; Han et al. 2011; Fan and Huang 2012), there has been few applications in other domains. Ren et al. (2015) developed a model for optimizing the life cycle cost of biofuel supply chain by considering uncertainties of different factors, and attempted to minimize the cost of the cycle. At the end they have developed a method to obtain an optimized solution from the solution intervals by introducing uptake coefficients and trying to minimize them so that the selected solution be more beneficial for stakeholders.

At the same time transition to a sustainable electricity sector is pressing and requires a comprehensive evaluation of each energy source in order to investigate their performance related to environmental and social attributes. These evaluations are a Multi Criteria Decision Making problem with often conflicting criteria being presented in different scales and formats. Previous research in this domain investigated different energy resources against sustainability criteria and proposed a framework for prioritizing renewable and conventional energy resources (Stein 2013; Kabak and Dağdeviren 2014; Büyüközkan and Güleryüz 2016). However despite the mentioned researches, applying fuzzy or grey MCDM techniques can overcome uncertainty within the decision makers' judgments or imprecise information and increase the validity of evaluation significantly. Sadeghi et al. (2012) applied Fuzzy AHP to obtain the weights of each criteria and Fuzzy TOPSIS to compare 4 renewable energy resources in Iran with respect to sustainability criteria. 
While application of fuzzy numbers and systems are numerous in prioritizing the electricity generation methods (Kaya and Kahraman 2009; Streimikiene et al. 2012; Tasri and Susilawati 2014; Şengül et al. 2015; Afsordegan et al. 2016), Grey based methods also have had an extensive application for evaluation of sustainable energy resources and while in the most of the cases, the imprecise information are available in the format of uniformly distributed within a lower and upper bound, defining fuzzy membership functions for them is a hard or impractical job. Thus application of grey numbers can have a significant advantageous over fuzzy numbers in these situations. Çelikbilek and Tüysüz (2016) by applying Grey-DEMATEL and Grey-ANP obtain the weights of criteria for assessment of sustainable performance of renewable energy sources and through Grey-VIKOR they compute the final ranking of the resources.

Grey relational analysis is one of the distinguished method among MCDM grey techniques and one of its advantageous features is the ability to assess quantitative and qualitative relationships between factors and variables using a relatively small amount of data (Arce et al. 2015). This method has been used by several researchers assessment of energy systems' sustainable performance (Xu et al. 2011; Liu et al. 2013) and selecting the best technology (Sarucan et al. 2011; Manzardo et al. 2012; Ren et al. 2012).

In this paper we propose a framework for obtaining the optimal electricity generation mix, in which firstly, we have done a comprehensive GRA based evaluation for both environmental and social performance of the available sources in our case study by considering various types of data and measurements along with uncertainties associated with them. Then, by linking the MCDM evaluations and grey linear multi objective programming (GLMOP) created an MODM problem. MCDM evaluation of criteria and utilization of the results as coefficients in the optimization problem can reduce the number of required objective functions and also enable us to include more information in our model, which some of them are quantifiable and hard to include as a separated objective function. As a result the model is going to be smaller and easier to solve and at the same contain considerable amount of factors. Through considering the financial aspects, emissions and sustainability score of each source, we have covered all the sustainability aspects in our optimization and address the uncertain nature of the problem by applying grey linear programming. In this way we provide a significantly improved approach to those of the existing literature which are limited to either optimization over several objectives, by limited consideration of uncertainties, or just simply ranking the existing renewable and non-renewable sources based against various criteria.

For our case study we focus on the UK, because it combines several unique energy policy features which provide an ideally complex testbed for our proposed methodological approach. Some of the specificities of the UK power sector include its long-term commitment for energy decarbonisation (Sithole et al. 2016), energy market innovations such as capacity market and demand side management systems (Strbac 2008; Warren 2014), relatively low capacity margin (Newbery 2016) and vocal public debate about energy policy (Lilliestam and Hanger 2016).

This manuscript is structured as follows: after this introduction we continue in Sect. 2 where we present the integrated approach of GRA and IGLP and the process for solving the problem as well as the methodologies applied in this paper and then following with Sect. 3 where we present the GRA evaluation with respect to environmental and social factors and defining the related factors and criteria. In Sect. 4 we describe the optimization model and present the definition of all the coefficients. The results are shown in Sect. 5 and diagrams associated with them are depicted. Eventually we discuss our results and their policy implications in Sect. 6 and in Sect. 7 we provide concluding remarks, future research suggestions and limitations. 


\section{The proposed integrated approach}

In this study we applied an integrated approach of Grey numbers, grey relational analysis and multi objective grey linear programming in order to obtain the optimized electricity production mix from available resources in the UK. At first we used Grey Relational Analysis to evaluate and rank the electricity generation resources with respect to environmental and social criteria. Then the rankings were entered to a MODM problem to determine the optimal share of electricity that should be produced by each resource. In order to consider the uncertainty of decision makers in the evaluation process, grey linguistic terms were used and to deal with inaccurate data and approximations in the Multi Objective optimization, Grey Linear programming was applied. Figure 1 shows the solution procedure for optimizing mixed electricity production.

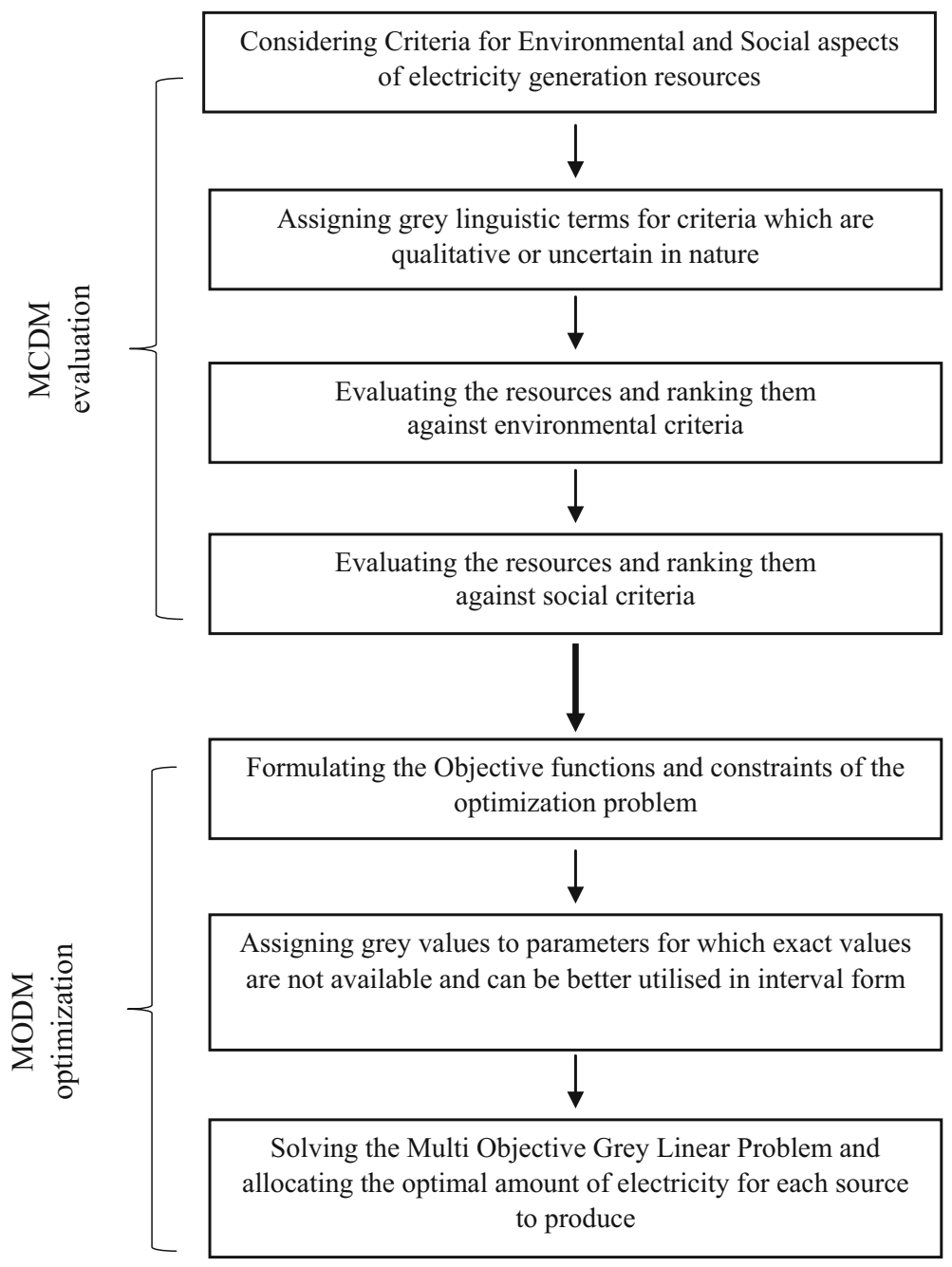

Fig. 1 Solution procedure of GRA-MOGLP integrated approach 


\subsection{Grey system theory}

Grey system theory introduced by Deng (1982) is an effective model for uncertain systems which contains known information as well as unknown information. In order to cover uncertainties involved in a system, grey system uses grey numbers and grey variables. In grey systems information classified into three categories of white (known information), black (completely unknown information) and grey (partially known and partially unknown information). For defining a grey number let $X$ be the universal set and $x \in X$. Then a grey set $G$ of $X$ is defined by its two mappings in Eqs. 1 and 2:

$$
\begin{aligned}
& \bar{\mu}_{G}(x): x \rightarrow[0,1] \\
& \underline{\mu}_{G}(x): x \rightarrow[0,1]
\end{aligned}
$$

In the aforementioned equations, $\bar{\mu}_{G}(x)$ and $\underline{\mu}_{G}(x)$ are upper and lower membership functions respectively. Generally Grey numbers are expressed as:

$$
\otimes G=\left.\bar{G}\right|_{\underline{\mu}} ^{\mu}
$$

While the lower and upper memberships can be estimated and an interval valued grey number with lower and upper bound can be defined as:

$$
\otimes G=[\underline{G}, \bar{G}]
$$

If we assume $\otimes G_{1}=\left[G_{1}, \overline{G_{1}}\right]$ and $\otimes G_{2}=\left[G_{2}, \overline{G_{2}}\right]$ two Grey interval numbers then, the main operations on grey numbers are performed by following:

$$
\begin{aligned}
& \otimes \mathrm{G} 1+\otimes \mathrm{G} 2=[\underline{G 1}+\underline{G 2}, \overline{G 1}+\overline{G 2}] \\
& \otimes \mathrm{G} 1-\otimes \mathrm{G} 2=[\underline{G 1}-\overline{G 2}, \overline{G 1}-\underline{G 2}] \\
& \otimes \mathrm{G} 1 \times \otimes \mathrm{G} 2=[\underline{\min }(\underline{G 1 G 2}, \underline{G 1} \overline{G 2}, \overline{G 1} \underline{G 2}, \overline{G 2 G 1}), \max (\underline{G 1 G 2}, \underline{G 1} \overline{G 2}, \overline{G 1} \underline{G 2}, \overline{G 2 G 1})] \\
& \otimes \mathrm{G} 1 \div \otimes \mathrm{G} 2=[\underline{G 1}, \overline{G 1}] \times\left[\frac{1}{\overline{G 2}}, \underline{\underline{G 2}}\right]
\end{aligned}
$$

Also the lengths of a grey number can be calculated as follows:

$$
L(\otimes G)=|\bar{G}-\underline{G}|
$$

\subsection{Grey relational analysis}

A multi-criteria Problem consists of a set of $m$ alternatives $\left(y_{1}, y_{2}, \ldots, y_{m}\right)$ and $n$ criteria $\left(k_{1}, k_{2}, \ldots, k_{n}\right)$ and form a decision matrix as Eq. (10).

$$
D M=\left[\begin{array}{cccc}
d_{11} & d_{12} & \cdots & d_{1 n} \\
d_{21} & d_{22} & \cdots & d_{2 n} \\
\vdots & \vdots & \cdots & \vdots \\
d_{m 1} & d_{m 2} & \cdots & d_{m n}
\end{array}\right]=\left[d_{i j}\right] \text { for } i=1,2, \ldots, m ; \quad \text { and } j=1,2, \ldots, n \text {, }
$$

where $d_{i j}$ is the performance value of alternative $y_{i}$ against criterion $k_{j}$. Final goal of all MCDM approaches is to evaluate the alternatives with respect to the related criteria and finally rank the alternatives or compute an evaluation score to support decision making. As an MCDM approach, GRA is a technique to determine the relation and connection of a set of alternatives with an aspired reference, called the ideal sequence, which is derived from 
the best performance of all the alternatives. This relation is called grey relational coefficient and after calculating the grey relational coefficient between all the alternatives and the ideal sequence the grey relational grades for all the alternatives are calculated and compared to determine the ranking and score of each alternative. The steps of GRA is based on the following:

Step 1 Normalizing the decision matrix through one of the Eqs. 11, 12 or 13 if the criteria is belonged to benefit (higher the better), cost (lower the better) criteria or the value of the criteria has to be closer to a Desired Amount (DA) respectively:

$$
\begin{aligned}
r_{i j}= & \frac{d_{i j}-\min \left(d_{i j}, i=1,2, \ldots, m\right)}{\max \left(d_{i j}, i=1,2, \ldots, m\right)-\min \left(d_{i j}, i=1,2, \ldots, m\right)} \\
& \quad \text { for } i=1,2, \ldots, m \text { and } j=1,2, \ldots, n \\
r_{i j}= & \frac{\max \left(d_{i j}, i=1,2, \ldots, m\right)-d_{i j}}{\max \left(d_{i j}, i=1,2, \ldots, m\right)-\min \left(d_{i j}, i=1,2, \ldots, m\right)} \\
& \quad \text { for } i=1,2, \ldots, m \text { and } j=1,2, \ldots, n, \\
r_{i j}= & 1-\frac{\left|d_{i j}-D A\right|}{\max \left\{\max \left(d_{i j}, i=1,2, \ldots, m\right)-D A, D A-\min \left(d_{i j}, i=1,2, \ldots, m\right)\right\}} \\
& \text { for } i=1,2, \ldots, m \text { and } j=1,2, \ldots, n .
\end{aligned}
$$

Step 2 Defining the reference sequence (ideal sequence) $R_{0}=\left(R_{0,1}, R_{0,2}, \ldots, R_{0, n}\right)$ based on Eq. 14 as follows:

$$
R_{0, j}=\max _{i=1, \ldots, m}\left(r_{i j}\right), j=1,2, \ldots, n .
$$

Step 3 Grey Relational coefficient is being used to determine how close (more connected) is the $r_{i j}$ to $R_{0, j}$ and the larger grey relational coefficient is, the closer $r_{i j}$ and $R_{0, j}$ are together. Grey relational coefficient is shown by $\gamma\left(r_{i j}, R_{0, j}\right)$ and calculated through Eq. 15 as follows:

$$
\gamma\left(r_{i j}, R_{0, j}\right)=\frac{\min _{i} \min _{j} \Delta_{i j}+\zeta \max _{i} \max _{j} \Delta_{i j}}{\Delta_{i j}+\zeta \max _{i} \max _{j} \Delta_{i j}}
$$

where $\Delta_{i j}=\left|R_{0, j}-r_{i j}\right|$, and $\zeta$ is the distinguished coefficient $(\zeta \in[0,1])$. Adopting different values for distinguishing coefficient will result in compressing or expanding the range of grey relational coefficient and usually $\zeta=0.5$ is being used by researchers.

Step 4 After obtaining all the grey relational coefficients, grey relational grade between alternative $i$ and reference sequence, which is shown by $\Gamma_{i}$, is computed based on Eq. 16 as follows:

$$
\Gamma_{i}=\sum_{j=1}^{n} w_{j} \gamma\left(r_{i j}, R_{0, j}\right) \quad \text { for } i=1,2, \ldots, m .
$$

Grey relational grades represent the level of correlation between reference sequence and alternatives, as the larger grade between an alternative and reference sequence determine more similarity between them; hence, the respective alternative rank higher in the evaluation.

\subsection{Grey interval linear programming}

Grey Interval Linear Programming (GILP) is part of an optimization category called interval linear programming and the solution to it is obtained by application of interval linear 
programming concepts. A GRA model can be first introduced as Model (1).

$\max f: \otimes C \otimes X$

Subject to:

$\otimes A \otimes X \leq \otimes B$

Model (1)

And $\otimes X \geq 0$

In the above model,

$$
\begin{aligned}
& \otimes C=\left\{\otimes\left(c_{1}\right), \otimes\left(c_{2}\right), \ldots, \otimes\left(c_{n}\right)\right\} \\
& \otimes B^{T}=\left\{\otimes\left(b_{1}\right), \otimes\left(b_{2}\right), \ldots, \otimes\left(b_{m}\right)\right\} \\
& \otimes X^{T}=\left\{\otimes\left(x_{1}\right), \otimes\left(x_{2}\right), \ldots, \otimes\left(x_{n}\right)\right\}
\end{aligned}
$$

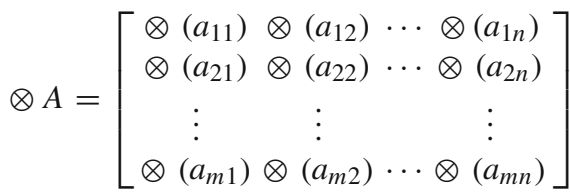

And as far as all the above vectors are grey for $\otimes\left(c_{j}\right), \otimes\left(b_{i}\right), \otimes\left(x_{j}\right)$ and $\otimes\left(a_{i j}\right)$ we have:

$$
\begin{aligned}
\otimes\left(c_{j}\right) & =\left[\underline{\otimes}\left(c_{j}\right), \bar{\otimes}\left(c_{j}\right)\right]=c_{j}^{ \pm} \text {and } \underline{\otimes}\left(c_{j}\right)=c_{j}^{-}, \underline{\otimes} ; \forall j, \\
\otimes\left(b_{i}\right) & =\left[\underline{\otimes}\left(b_{i}\right), \bar{\otimes}\left(b_{i}\right)\right]=b_{i}^{ \pm} \text {and } \underline{\otimes}\left(b_{i}\right)=b_{i}^{-}, \bar{\otimes} ; \forall i, \\
\otimes\left(x_{j}\right) & =\left[\underline{\otimes}\left(x_{j}\right), \bar{\otimes}\left(x_{j}\right)\right]=x_{j}^{ \pm} \text {and } \underline{\otimes}\left(x_{j}\right)=x_{j}^{-}, \bar{\otimes} ; \forall j, \\
\otimes\left(a_{i} j\right) & =\left[\underline{\otimes}\left(a_{i} j\right), \bar{\otimes}\left(a_{i} j\right)\right]=a_{i j}^{ \pm} \text {and } \underline{\otimes}\left(a_{i} j\right)=a_{i j}^{-}, \bar{\otimes} ; \forall i, j .
\end{aligned}
$$

Since all the parameters in the model are in interval grey form, the optimal solution also will be in interval grey form as follows:

$\otimes f=[\underline{\otimes} f, \bar{\otimes}]$ and $\otimes X^{* T}=\left[\otimes\left(x_{1}^{*}\right), \otimes\left(x_{2}^{*}\right), \ldots, \otimes\left(x_{j}^{*}\right)\right]$ where $\otimes\left(x_{j}^{*}\right)=\left[\underline{\otimes} x_{j}^{*}, \bar{\otimes}\right]$.

In order to solve model (1), Huang et al. (1992) proposed the two step method (TSM) which transforms the main problem into two sub-models, the first for obtaining lower bound and the second for calculating the upper bound of objective function. Later Fan and Huang (2012) completed the TSM method further and called it Enhanced Two Step Method (ETSM) based on following. The advantageous of ETSM to TSM is that it guarantee no violation of the solution from best-cast constraints. If both the lower and upper bounds of the objective function $\left(f^{ \pm}\right)$and right hand side of the constraints $\left(b^{ \pm}\right)$are positive and for $n$ interval coefficients in model (1), $k$ of them be positive $\left(c_{j}^{ \pm} \geq 0 ; j=1,2, \ldots, k\right)$ and $n-k$ of them be negative $\left(c_{j}^{ \pm} \leq 0 ; j=k+1, k+2, \ldots, n\right)$, then the first sub-model for obtaining the lower bounds can be shown as follows:

$$
\max f^{-}=\sum_{j=1}^{k} c_{j}^{-} x_{j}^{-}+\sum_{j=k+1}^{n} c_{j}^{-} x_{j}^{+}
$$

Subject to:

$$
\sum_{j=1}^{k} a_{i j}^{+} x_{j}^{-}+\sum_{j=k+1}^{n} a_{i j}^{+} x_{j}^{+} \leq b_{i}^{-} \text {for } i=1,2, \ldots, m,
$$




$$
\begin{aligned}
& x_{j}^{-} \geq 0 \text { for } j=1,2, \ldots, k, \\
& x_{j}^{+} \geq 0 \text { for } j=k+1, k+2, \ldots, n .
\end{aligned}
$$

Through solving model (2) lower bounds for optimum value of $x_{j, o p t}^{ \pm} ; j=1,2, \ldots, k$ and upper bounds for optimum value of $x_{j, o p t}^{ \pm} ; j=k+1, k+2, \ldots, n$ can be obtained. After solving model (2) the second sub-model for the main problem can be proposed as model (3) and by solving it the upper bound for objective function can be achieved.

$$
\max f^{+}=\sum_{j=1}^{k} c_{j}^{+} x_{j}^{+}+\sum_{j=k+1}^{n} c_{j}^{+} x_{j}^{-}
$$

Subject to:

$$
\begin{aligned}
& \sum_{j=1}^{k} a_{i j}^{-} x_{j}^{+}+\sum_{j=k+1}^{n} a_{i j}^{-} x_{j}^{-} \leq b_{i}^{+} \text {for } i=1,2, \ldots, m, \\
& \sum_{j=1}^{l_{i 1}} a_{i j}^{-} x_{j}^{+}+\sum_{j=l_{i 1}+1}^{k} a_{i j}^{-} x_{j o p t}^{-}+\sum_{j=k+1}^{l_{i 2}} a_{i j}^{-} x_{j}^{-}+\sum_{j=l_{i 2}+1}^{n} a_{i j}^{-} x_{j o p t}^{+} \leq b_{i}^{+} \text {for } i=1,2, \ldots, m, \\
& x_{j}^{+} \geq x_{j, \text { opt }}^{-} \text {for } j=1,2, \ldots, k, \\
& x_{j}^{+} \leq x_{j, \text { opt }}^{-} \text {for } j=k+1, k+2, \ldots, n, \\
& x_{j}^{+} \geq 0 \text { for } j=1,2, \ldots, k, \\
& x_{j}^{-} \geq 0 \text { for } j=k+1, k+2, \ldots, n,
\end{aligned}
$$

where:

$$
\begin{aligned}
& a_{j}^{ \pm} \geq 0 j=1,2, \ldots, l_{i 1} ; j=l_{i 2}+1, l_{i 2}+2, \ldots, n, \\
& a_{j}^{ \pm} \leq 0 j=l_{i 1}+1, l_{i 1}+2, \ldots, k ; j=k+1, k+2, \ldots, l_{i 2} .
\end{aligned}
$$

In the aforementioned model, $x_{j, o p t}^{-}$and $x_{j, o p t}^{+}$are the optimum values for decision variables after solving model (2).

\subsection{Multi-objective grey interval programming}

The solution to a Multi-Objective Grey Linear Programming can be obtained through a multi-stage procedure, where at first each objective function, whether minimization or maximization, should be optimized separately by considering all the constraints in the model. These optimizations can be solved by applying model (1)-(3). Then membership functions for maximization and minimization objective functions should be developed. Assume the optimum value for $l$ th objective function, which has to be maximized, is $f_{l}^{*}=\left[\underline{\otimes} f_{l}^{*}, \bar{\otimes} f_{l}^{*}\right]$, so then the membership function can be as Eq. 21.

$$
\mu_{l}(x)=\left\{\begin{array}{cl}
1 & \text { if } f_{l}(x) \geq \bar{\otimes} f_{l}^{*}, \\
\overline{f_{l}(x)-\underline{\otimes} f_{l}^{*}} & \text { if } f_{l}(x) \leq \underline{\otimes} f_{l}^{*} .
\end{array}\right.
$$

Increase of $f_{l}(x)$ results in increase of the membership function of $\mu_{l}$. 

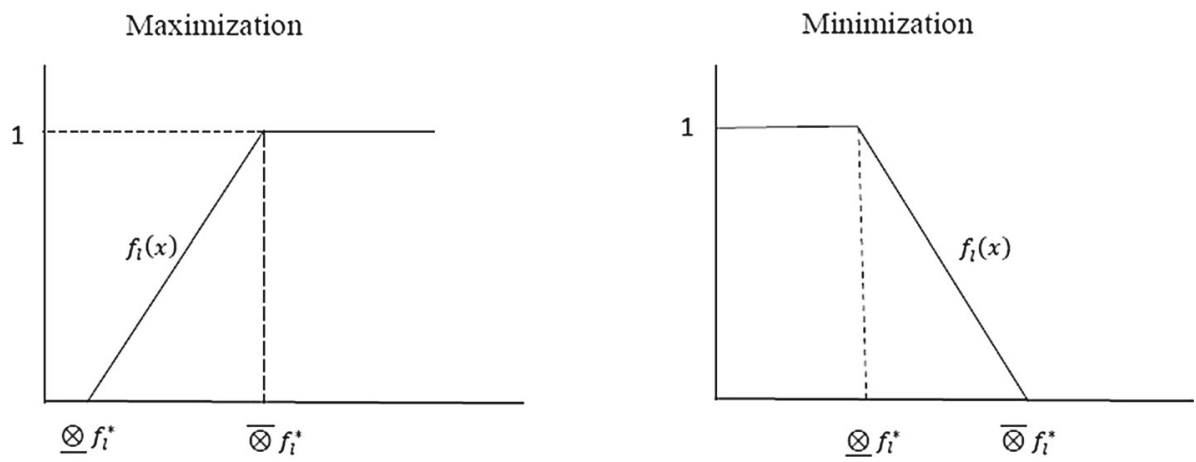

Fig. 2 Minimization and maximization of membership functions

In the same way, assume the optimum value for $l$ th objective function, which has to be minimized, is $f_{l}^{*}=\left[\underline{\otimes} f_{l}^{*}, \bar{\otimes} f_{l}^{*}\right]$, so then the membership function can be defined as Eq. 22.

$$
\mu_{l}(x)=\left\{\begin{array}{cl}
1 & \text { if } f_{l}(x) \leq \underline{\otimes} f_{l}^{*}, \\
\bar{\otimes} f_{l}^{*}-\underline{\otimes} f_{l^{*}} & \text { if } f_{l}(x) \geq \underline{\otimes} f_{l}^{*} . \\
\overline{\bar{\otimes} f_{l}^{*}-\underline{\otimes} f_{l}^{*}} & \text {. }
\end{array}\right.
$$

Decreasing of $f_{l}(x)$ leads to increasing the membership function of $\mu_{l}$. Figure 2 shows the diagrams for maximization and minimization membership functions.

Finally, after solving all the single objective optimization problems and formulating the objective functions, through following the single objective model (4), the optimal answers for our multi-objective model will be obtained.

$$
\max \sum_{l=1}^{p} w_{l} \mu_{l}(x)
$$

Subject to:

$$
\begin{aligned}
& \mu_{l}(x) \leq 1 \\
& \otimes A \otimes X \leq \otimes B,
\end{aligned}
$$

and $\otimes X \geq 0$.

Model (4) is interval linear programming itself and can be solved through models (1)-(3).

\section{Evaluation models}

As previously stated the goal of this paper is to suggest an optimal electricity sector mix based on a range of available resources and considering sustainability criteria. Prior to designing the optimization problem, as an essential coefficient for the model, sources have to be assessed with respect to environmental and social factors. In order to establish an evaluation multicriteria model to rank the sources, defining related criteria is an important step. For this manuscript these criteria were defined based on a review of research (Afgan and Carvalho 2002; Kaldellis et al. 2006; Wang et al. 2009; Evans et al. 2009; Conca 2012; Macknick et al. 2012; Santoyo-Castelazo and Azapagic 2014; Maxim 2014) and best practice reports in the EU (EEA 2013; JRC 2013) and UK (DECC 2013) and expert opinion. After collecting all the criteria being used in the literature, following criteria has been selected through Delphi 
Table 1 Environmental criteria and their descriptions

\begin{tabular}{|c|c|c|}
\hline Criteria & Description & Measuring unit, type \\
\hline Heavy metal emissions & $\begin{array}{l}\text { Amount of heavy metals released to the } \\
\text { environment by generating electricity from } \\
\text { fuel combustion }\end{array}$ & $\begin{array}{l}\text { Interval grey number } \\
\quad(\mathrm{g} / \mathrm{GWh})\end{array}$ \\
\hline Water consumption & $\begin{array}{l}\text { Water withdrawals mainly for use in cooling } \\
\text { systems of thermal power stations }\end{array}$ & Crisp value $\left(\mathrm{m}^{3} / \mathrm{GWh}\right)$ \\
\hline Effect on global Warming & $\begin{array}{l}\text { Given the amount of } \mathrm{CO}_{2}, \mathrm{NO} x \text { and other } \\
\text { greenhouse gases being released by each } \\
\text { system for generating one GWh electricity, } \\
\text { experts express their opinion on this criteria. }\end{array}$ & Linguistic term \\
\hline Land use & $\begin{array}{l}\text { Land occupied by energy generation facilities } \\
\text { against their expected energy production } \\
\text { throughout their lifespan }\end{array}$ & $\begin{array}{l}\text { Interval grey number } \\
\left(\mathrm{m}^{2} / \mathrm{MWh}\right)\end{array}$ \\
\hline $\begin{array}{l}\text { Disturbance of ecological } \\
\text { balance }\end{array}$ & $\begin{array}{l}\text { Energy Generation systems through the land } \\
\text { they occupy during installation and waste they } \\
\text { produce during their operations can cause } \\
\text { stress and disruption to ecosystems. }\end{array}$ & Linguistic term \\
\hline $\begin{array}{l}\text { Particulate matter } \mathrm{PM}_{10} \\
\text { and Particulate matter } \\
\mathrm{PM}_{25}\end{array}$ & $\begin{array}{l}\text { Particulate matter emissions have been } \\
\text { considered separately for } \mathrm{PM}_{10} \text { and } \mathrm{PM}_{2.5} \text {. } \\
\text { Particulate matter emissions pose significant } \\
\text { risks for human health depending on size, } \\
\text { distribution, microstructure and chemical } \\
\text { composition. }\end{array}$ & $\begin{array}{l}\text { Interval grey number } \\
(\mathrm{kg} / \mathrm{GWh})\end{array}$ \\
\hline
\end{tabular}

method (for more information about Delphi technique reader may refer to Sackman 1974) by the experts as the most relevant and crucial ones to be used in our research. The criteria selected for environmental and social evaluation and their brief definitions are available in Tables 1 and 2 .

The power production options have been evaluated against the aforementioned criteria. For cases best described by crisp data, the precise number for the criteria has been considered. For cases with data uncertainty or data being available in an interval range, the interval value in form of a grey number has been used. Moreover, where the opinions of experts were needed for the criteria, by the means of linguistic terms their opinions have been considered and entered into the decision matrix. After that linguistic variables have been transformed into grey numbers.

\section{Optimization model}

In this section Grey Multi-Objective Linear Model is proposed for resolving the problem of optimal electricity fuel mix problem. The decision variables, objective functions, constraints and coefficients used in our model are described in detail in the following sections. The aim of our multi-objective approach is to share the electricity generation between seven available systems based on different resources i.e. Coal, Oil, Gas, Nuclear, Biomass, Hydro, Wind Power and Solar. The proposed resource mix should minimize the overall costs of generation, the amount of imported fuel, the emissions caused by power generation and simultaneously maximize the environmental and social benefits of installing and producing electricity by our systems. Basics of the model is derived from previous similar research in the field (Linares and Romero 2000; Cong 2013; Cabello et al. 2014) with few changes, some 
Table 2 Social criteria and their descriptions

\begin{tabular}{|c|c|c|}
\hline Criteria & Description & Measuring unit, type \\
\hline Job creation & $\begin{array}{l}\text { Energy production facilities are large infrastructure } \\
\text { project that employ more people during } \\
\text { construction phase and fewer during operation. } \\
\text { Here we used levelised data based on expected } \\
\text { energy output during project lifespan }\end{array}$ & $\begin{array}{l}\text { Crisp value (job } \\
\text { years/GWh) }\end{array}$ \\
\hline Social acceptability & $\begin{array}{l}\text { Social acceptability expresses the overview of } \\
\text { opinions related to the energy systems by the local } \\
\text { population regarding the hypothesized realization } \\
\text { of the projects under review from the consumer } \\
\text { point of view }\end{array}$ & Linguistic term \\
\hline Mortality rate & $\begin{array}{l}\text { Number of deaths occurring during the production } \\
\text { of certain energy resources. It is } \\
\text { a combination of actual direct deaths and } \\
\text { epidemiological estimates }\end{array}$ & $\begin{array}{l}\text { Interval grey number } \\
\text { (Deaths/GWh) }\end{array}$ \\
\hline $\begin{array}{l}\text { External costs associated } \\
\text { with health }\end{array}$ & $\begin{array}{l}\text { Energy facilities are associated with numerous } \\
\text { externalities. Here we are only taking into } \\
\text { consideration those that are directly linked to } \\
\text { human health (excluding those linked to } \\
\text { ecosystem damages etc) }\end{array}$ & $\begin{array}{l}\text { Interval grey number } \\
(€ / \mathrm{GWh})\end{array}$ \\
\hline
\end{tabular}

common concepts about fixed and variables costs as well as some innovative constraints and objective functions developed for this research. The importance weights of all the objective functions have been considered equally throughout the multi-criteria optimization.

\subsection{Decision variables}

The capacity that needs to be available or be installed is our first decision variable. Being denoted by $Y_{i}(i=1,2, \ldots, m)$ for each system $i$ in Megawatts (MW) and called installation capacity, determines the nominal power output that can be generated by each system type aggregated across the country. $X_{k i}(i=1,2, \ldots, m)$ represents the hourly electricity generation of $i$ th system in the $k$ th period $(k=1,2, \ldots, T)$. In this research time periods are considered in intervals of $6 \mathrm{~h}$ from 00 am to $24 \mathrm{pm}$ of each day continuously during a year. The number of hours in the $k$ th period is denoted by $t_{k}$. Moreover, the demand for period $k$ is denoted by $d_{k}$ and is defining the overall demand in the country during period $k$ in MWh.

\subsection{Objective functions}

As previously discussed, in order to optimize the electricity generation, the objective functions consider financial, environmental, social and reduction of fuel import dependence. For financial objective annual costs, for environmental objective emissions and environmental scores and ranks, and for social objective the social scores and ranks which were obtained through GRA in Sect. 3 have been considered.

\subsubsection{Annual cost of electricity generation}

Annual cost include fixed costs which are related to installation capacity and variable costs which affect the actual produced energy. The objective function is showed in Eq. 23 and should be minimized. 


$$
\operatorname{Min}(\text { Annual Cost }): \sum_{i=1}^{m}\left(C a C_{i}+F O M_{i}\right) Y_{i}+\sum_{i=1}^{m}\left(V M C_{i}+F u C_{i}\right) \sum_{k=1}^{T} t_{k} X_{k i}
$$

where $C a C_{i}$ capital cost for installing system $i$ per MW, $F O M_{i}$ fixed operation and maintenance cost for system $i$ per MW, $V M C_{i}$ variable operation and maintenance cost for system $i$ per MW, $F u C_{i}$ fuel cost for system $i$ per MW which obtained by multiplication of fuel price and fuel consumption for system $i$ to produce 1 MW of electricity.

Note that all the costs associated with Eq. 23 are in interval grey format to deal with uncertainties and imprecision exist with the price fluctuations and estimations.

\subsubsection{Independence from imported fuel}

Minimizing the amount of energy being generated by imported fuel can reduce the dependence of our grid from foreign resources and control its vulnerability. Thus this objective function tries to minimize the amount of electricity generation by imported fuel and is based on Eq. 24.

$$
\operatorname{Min} I V: \sum_{i=1}^{m} \sum_{k=1}^{T} I P_{i} t_{k} X_{k i}
$$

where $I P_{i}$ share of fuel being consumed hourly and has to be imported for system $i$ and this coefficient is in grey interval format.

\subsubsection{Environmental consideration}

In order to achieve this objective, two objective functions have been proposed in this study. In the first objective function the emissions of $\mathrm{CO}_{2}$ (and equivalent Greenhouse Gases) are being minimized. In the second objective function the scores which were calculated in Sect. 3 for system evaluation are being used as a weight coefficient in a maximizing objective function to maximize the value of environmental benefits in mixed electricity generation. Equations 25 and 26 show the two proposed objective functions for environmental considerations:

$$
\begin{array}{r}
\text { Min Emissions : } \sum_{i=1}^{m} \sum_{k=1}^{T} E_{i}^{\mathrm{CO}_{2}} t_{k} X_{k i} \\
\text { Max Environmental value: } \sum_{i=1}^{m} \sum_{k=1}^{T} \text { Escor }_{i} t_{k} X_{k i}
\end{array}
$$

where $E_{i}^{\mathrm{CO}_{2}} \mathrm{CO}_{2}$ being emitted by the $i$ th generating system based on MWh electricity of production, Escore $_{i}$ environmental scores obtained by GRA for each generation system.

\subsubsection{Social consideration}

Similar to the environmental consideration section, the scores are calculated by social evaluation of generation systems and are used as weight coefficient for this objective function. The aim is to maximize the social benefits by optimising the electricity resources mix. The objective function is shown in Eq. 27. 


$$
\text { Max Social score: } \sum_{i=1}^{m} \sum_{k=1}^{T} \operatorname{Sscor}_{i} t_{k} X_{k i} \text {, }
$$

where Sscore is the scores obtained by GRA for each generation system.

\subsection{Constraint}

A set of constraints for the optimization problem have been considered and are explained below.

\subsubsection{Electricity reliability and robustness}

Solar and wind energy systems produce variable (intermittent) output as they depend on stochastic weather. In order to guarantee generating enough power and being able to deal with peak electricity demand at any moment, we have to install conventional electricity generation systems (i.e. Oil, Gas, Coal and nuclear) with enough capacity to compensate for renewable systems in emergency periods. Equation 28 shows the constraint considered for this purpose.

$$
\sum_{i=1}^{I} A v_{i} C A_{i} P E_{i} Y_{i} \geq d^{*}(1+S),
$$

where $P E_{i}$ power efficiency of system $i$, that is the amount of energy produced and can be turned into useful electricity to be supplied to the grid for system $i, C A_{i}$ capacity coefficient of system $i$, that the fraction of the year when system $i$ is available, $A v_{i}$ technical availability factor for system $i$, that is the relation between number of hours that system $i$ is connected to the grid to the total hours in 1 year, $d^{*}$ demand at pick time, when it is mostly probable that renewable energy systems can be unavailable, $S$ slack coefficient, which is a reliability coefficient in percentage and determining a confidence level for generating electricity more than demand in case the energy demand is higher than our predictions.

\subsubsection{Diversity and limitation on conventional systems}

Relying on only one or a very limited number of resources for power generation is a risky strategy due to the inherent lack of diversity it causes. This is an issue widely identified in the energy security literature (Stirling 1994; Grubb et al. 2006) and several theoretical proposals have been made in order to improve system diversity. Moreover, environmental regulations force a degree of diversity by setting targets for renewable energy generation; or else by limiting generation by conventional thermal power stations to a given share of the total demand at period $t_{k}$. The Eqs. 29 and 30 guarantee that both of the above conditions will be satisfied.

$$
\begin{gathered}
\sum_{k=1}^{T} P E_{i} t_{k} X_{k i} \leq\left[\sum_{k=1}^{T} t_{k} d_{k}\right](1+S) L S C \quad \text { for } i=1,2, \ldots, m, \\
\sum_{k=1}^{T} P E_{i} t_{k} X_{k i} \leq\left[\sum_{k=1}^{T} t_{k} d_{k}\right](1+S) \text { Lim } \text { for } i=1,2, \ldots, I,
\end{gathered}
$$

where LSC \% limitation on producing electricity by a single source or system, Lim \% limitation on amount of electricity that should be produced by conventional systems. 
Where $I \cup V=m$, i.e., $I$ is the number of conventional generation systems, $V$ is the number of renewable generation systems and $m$ is the total number of generation systems.

\subsubsection{Demand satisfaction}

Generated electricity at period $t_{k}$ by all systems has to be able to satisfy the total demand in period $t_{k}$. Equation 32 makes sure this constraint will be satisfied.

$$
\sum_{i=1}^{m} P E_{i} t_{k} X_{k i} \geq t_{k} d_{k}(1+S) \quad \text { for } k=1,2, \ldots, T,
$$

Also this constraint guarantees that generated electricity by all systems to be able to satisfy the total demand in the period we are investigating.

\subsubsection{Hydro limitation}

Hydro power is limited by the availability of suitable geography in the UK.

$$
Y_{H y d r o} \leq \text { amount of available Hydro output in the country }
$$

\subsection{Additional constraints}

In addition to the aforementioned constraints there are few more conditions that are essential for our system to run correctly. Firstly, the technical constraint on relation between capacity and electricity production. Equation 33 ensures that the $i$ th available system capacity is adequate to produce enough power to meet demand.

$$
X_{k i} \leq A v_{i} C A_{i} Y_{i} \quad \text { for } i=1,2, \ldots, m \text { and } k=1,2, \ldots, T,
$$

And finally none zero constraints based on Eq. 34 and 35 .

$$
\begin{aligned}
X_{k i} & \geq 0 \\
Y_{i} & \geq 0
\end{aligned}
$$

Furthermore, the following assumptions are considered for the model development.

Assumption 1 There is no import and export of electricity in and out of the grid.

Assumption $275 \%$ of the demand should be satisfied by Coal, Gas, Nuclear, Oil and Biomass systems

Assumption 3 Upper bound for electricity generation by solar system is $5 \%$ of the overall electricity.

Assumption 4 Total available capacity to be installed by hydro system is $11,300 \mathrm{MWh}$.

Assumptions 2, 3 and 4 are based on realistic estimations of experts and The UK Renewable Energy Strategy document. 


\subsection{Data for optimization problem}

Based on Fig. 1 the first step of the integrated approach of GRA-MOGLP for this research is performing environmental and social evaluations of the generating resources to obtain Escore and Sscore for the model's objective functions. The decision matrix for environmental and social evaluations are shown in Tables 3 and 4 respectively. Our alternatives are consisted of 4 conventional generation systems of Coal, Gas, Nuclear and oil ( $i \in I$ and $i=1,2,3,4)$ and 4 renewable energy generation systems of Biomass, Wind Hydro and Solar $(i \in V$ and $i=$ $5,6,7,8)$. As previously mentioned the data has been collected via experts' opinions or extracted from EU (EEA 2013; JRC 2013) and UK (DECC 2013).

In Tables 3 and 4 transformation of grey linguistic terms to grey interval values is based on Table 5. The upper and lower bound of the grey interval values are determined through the consultation of experts in order to make the best distinction between alternatives and reflect their opinions.

After operating steps 1-4, which were previously explained in Sect. 2.2, the final results for grey relational grade of each alternative are obtained and alternatives are ranked according to their environmental and social performance (Table 6). Alternatives with higher grades are ranked as better ones. There was not a significant difference between the priority of the selected criteria in Delphi method and furthermore some of the criteria have been judged by an independent expert in the related field so the weights for social and environmental criteria in this research have been considered equally important. However while using the presented approach the decision makers can reflect their opinions about the weights and they are not necessarily equal.

The data, being used as input to our multi-objective model, were collected from various sources. Demand data is collected from National Grid published data ("Data Explorer | National Grid") for the 6 months of January to the end of June for year 2016. The upper bound and lower bound of demand is chosen $1 \%$ more and $1 \%$ less than actual demand respectively to cover the fluctuations happening within demand. Other coefficients as well as prices associated with different systems and their interval value ranges are based on Table 7. These prices are based on the most recent report of UK Department of Energy and Climate Change and the level of accuracy and ranges they have considered for the data they have published. Each period of $T$ for electricity generation is considered of a $6 \mathrm{~h}$ period, starting from 00:00am at January 1st of 2016. So for the 6 months under investigation we have a total of 728 time periods.

As can be seen all the prices except variable cost of operation and maintenance (VMC) are considered in an interval form based on their nature, the location of implementation and other conditions and can vary between an upper and a lower bound. Although the variations of variable costs were so small that in this paper we considered them by their crisp values.

Furthermore, the information for $\mathrm{CO}_{2}$ emissions of each system is shown in Table 8 .

\section{Results}

In order to solve the problem, we used large scale linear programing function in MATLAB software. Each of the objective functions has been separately coded and the lower and upper bounds of optimum solution were applied in multi-objective approach which was explained in Sect. 2.4 and the final results were computed. The model consists of 23,317 constraints for lower bound and 29,141 constraints for upper bound optimization problems for each single 


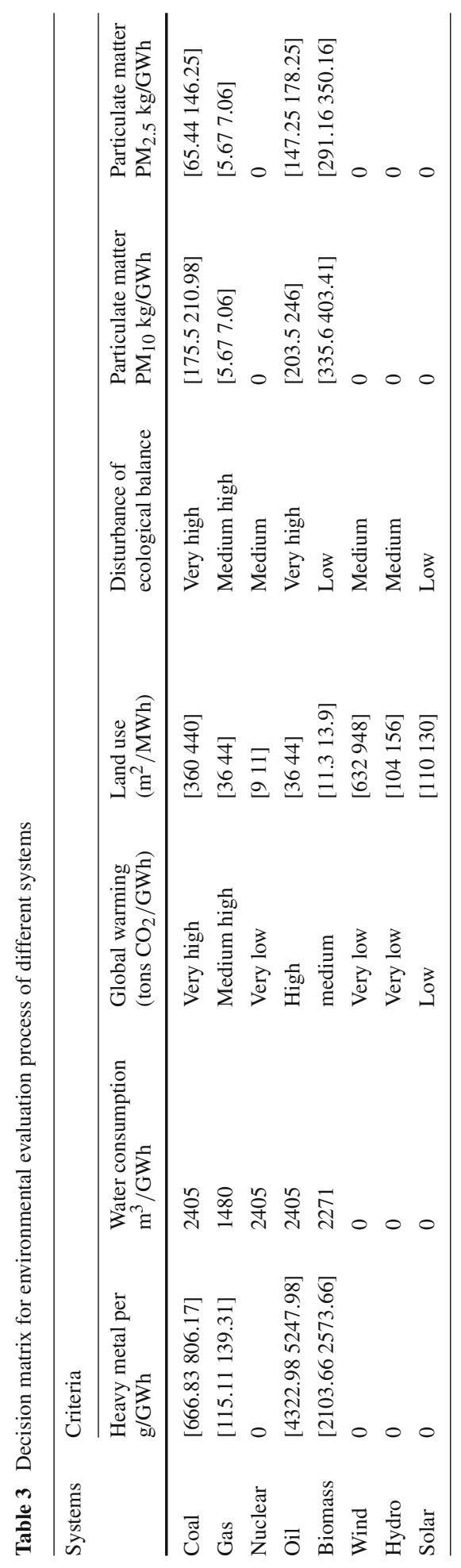


Table 4 Social decision matrix for evaluation process of different systems

\begin{tabular}{|c|c|c|c|c|}
\hline \multirow[t]{2}{*}{ Systems } & \multicolumn{4}{|l|}{ Criteria } \\
\hline & $\begin{array}{l}\text { Job creation } \\
\text { (Job } \\
\text { years/GWh) }\end{array}$ & $\begin{array}{l}\text { Social } \\
\text { acceptability }\end{array}$ & $\begin{array}{l}\text { Mortality rate } \\
\text { (deaths/TWh) }\end{array}$ & $\begin{array}{l}\text { External costs associated } \\
\text { with health } € / G W h\end{array}$ \\
\hline Coal & 0.11 & Low & $10-170$ & $10200-76500$ \\
\hline Gas & 0.11 & Medium & $3-5$ & $2000-8000$ \\
\hline Nuclear & 0.14 & Low & $0.00001-0.09$ & $1640-5740$ \\
\hline Wind & 0.17 & High & 0.15 & $340-1680$ \\
\hline Hydro & 0.55 & High & $0.00001-1.4$ & $200-6700$ \\
\hline Oil & 0.11 & Medium & 36 & $2000-8000$ \\
\hline Solar & 0.87 & High & 0.44 & 4380 \\
\hline Biomass & 0.21 & Medium & 24 & $1700-42500$ \\
\hline
\end{tabular}

Table 5 Grey interval numbers for linguistic terms

\begin{tabular}{ll}
\hline Interval term & Grey value \\
\hline Very high & {$\left[\begin{array}{ll}9 & 10\end{array}\right]$} \\
High & {$\left[\begin{array}{ll}7 & 9\end{array}\right]$} \\
Medium high & {$\left[\begin{array}{ll}5 & 7\end{array}\right]$} \\
Medium & {$\left[\begin{array}{ll}3 & 5\end{array}\right]$} \\
Low & {$\left[\begin{array}{ll}1 & 3\end{array}\right]$} \\
Very low & {$\left[\begin{array}{ll}0 & 1\end{array}\right]$} \\
\hline
\end{tabular}

Table 6 Final results for grey relational degree of each of the systems based on environmental and social GRA evaluation

\begin{tabular}{lllllllll}
\hline & Coal & Gas & Nuclear & Oil & Biomass & Wind & Hydro & Solar \\
\hline GRG for environment & 3.5539 & 5.3086 & 6.0476 & 3.4192 & 4.1640 & 6.0923 & 6.5122 & 6.5809 \\
GRG for social & 1.6927 & 2.6927 & 2.6751 & 2.4399 & 2.2887 & 3.3487 & 3.4735 & 3.9126 \\
\hline
\end{tabular}

objective function and 23,322 and 29,146 constraints for lower and upper bounds of multi objective optimization problems respectively. Due to availability of demand data for the sixth first months of the year 2016 we considered $T=728$ in our model. Through solving the problem, upper and lower bounds of final objective function indicate two different decision options. Lower bound value of objective function by considering upper bounds of constraints' coefficients and lower bounds of left hand side values, creates more conservative solution with lowest possible electricity generation and capacity. On the other hand, upper bound value for objective function by considering lower bounds of constraints' coefficients and upper bounds of left hand side values, due to increase in feasible area of the problem represents a solution which requires more electricity generation and consequently more capacity.

A direct comparison between the upper and lower values of the objective function can be considered in Fig. 3a and b. The differences are subtle and at the lower bound values benefit those resources with solar, gas, hydro, nuclear, biomass and wind.

The total electricity generation mix by each of the systems is shown in Fig. 4. 


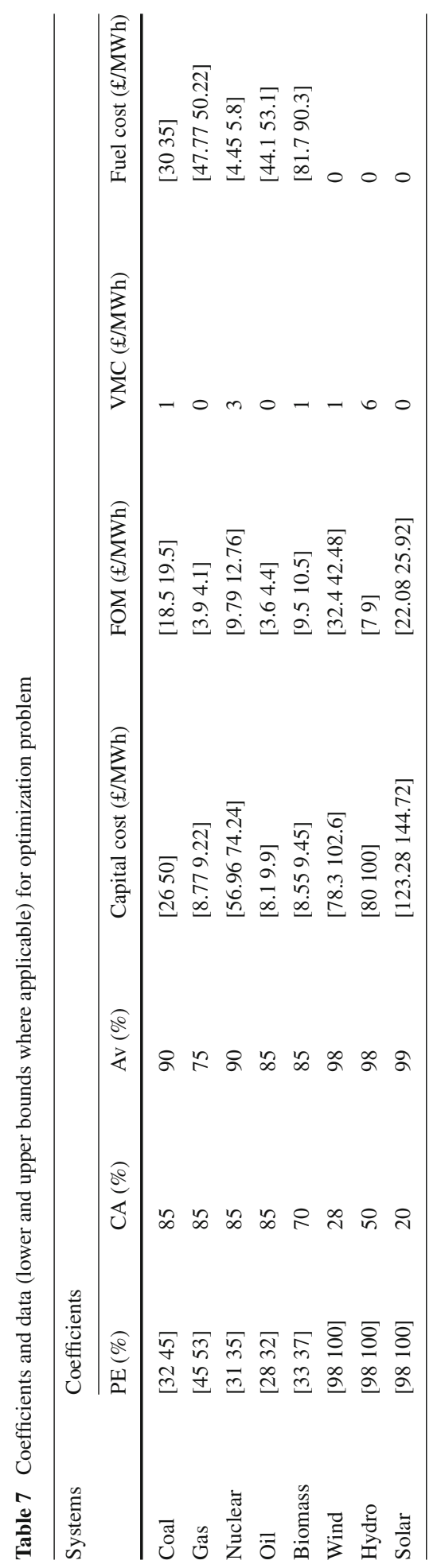




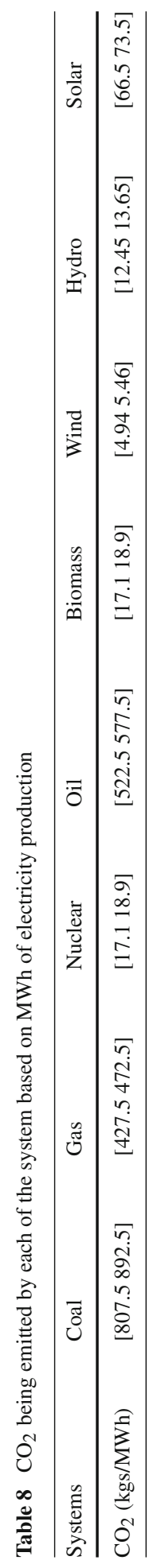



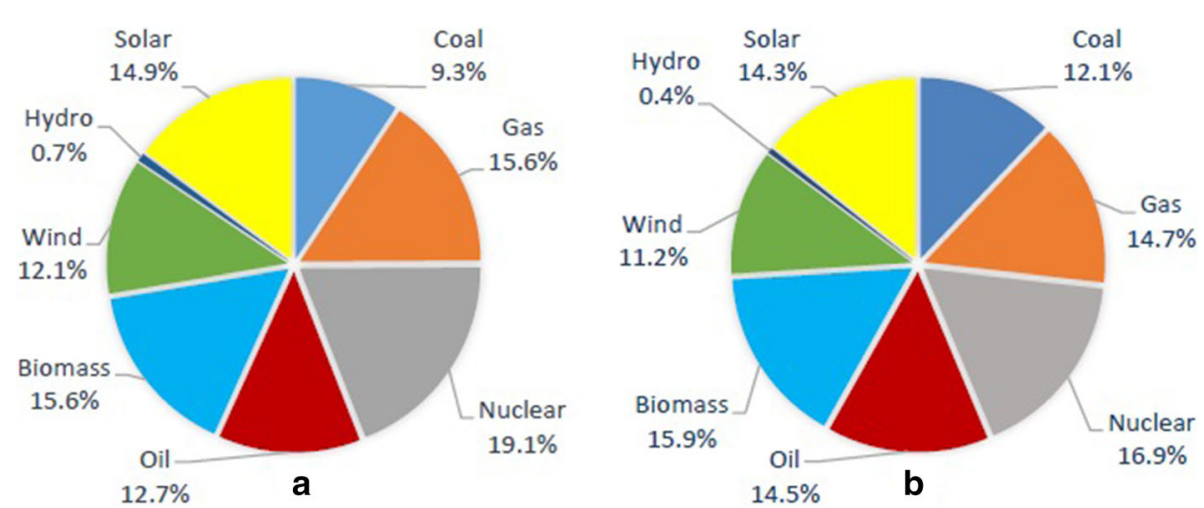

Fig. 3 Lower and upper bounds of capacity for multi-objective approach with equal weights. a Lower bound of capacity. $\mathbf{b}$ Upper bound of capacity
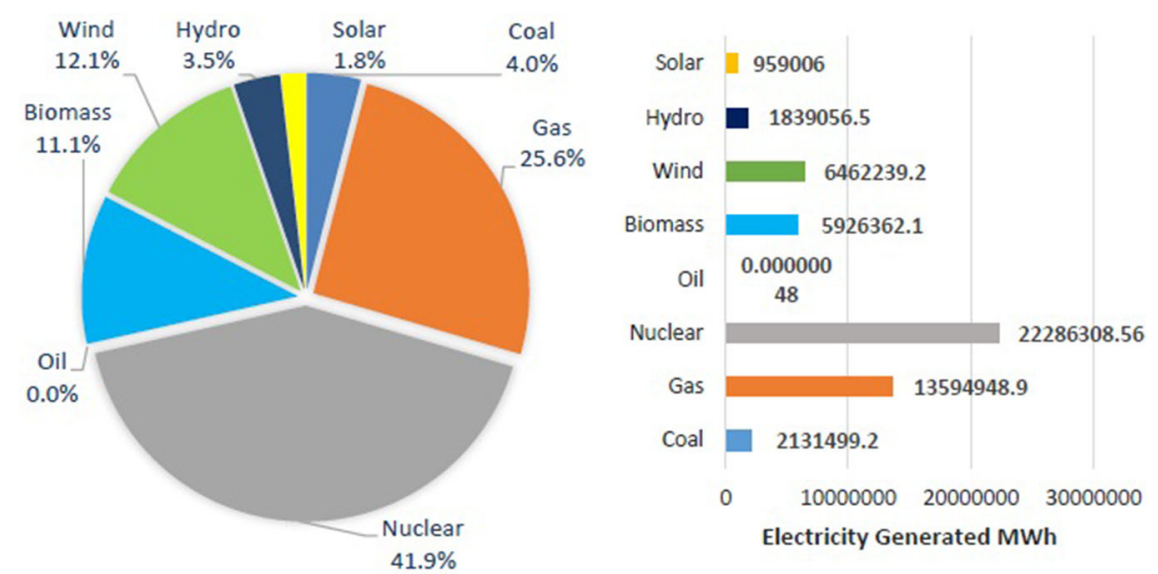

a
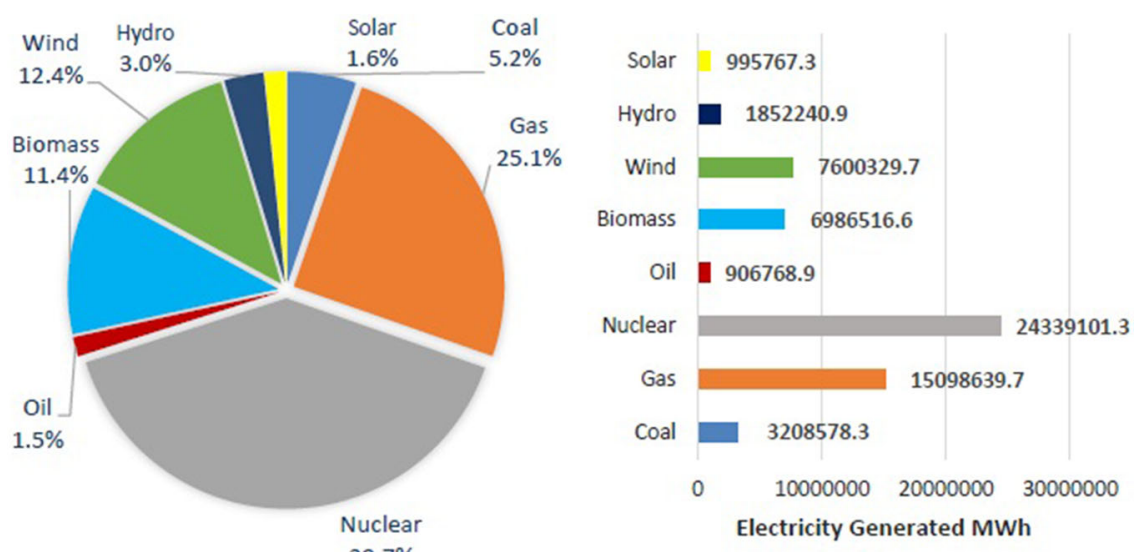

b

Fig. 4 Lower and upper bounds of electricity generation for multi-objective approach with equal weights. a Lower bound of generation. $\mathbf{b}$ Upper bound of generation 

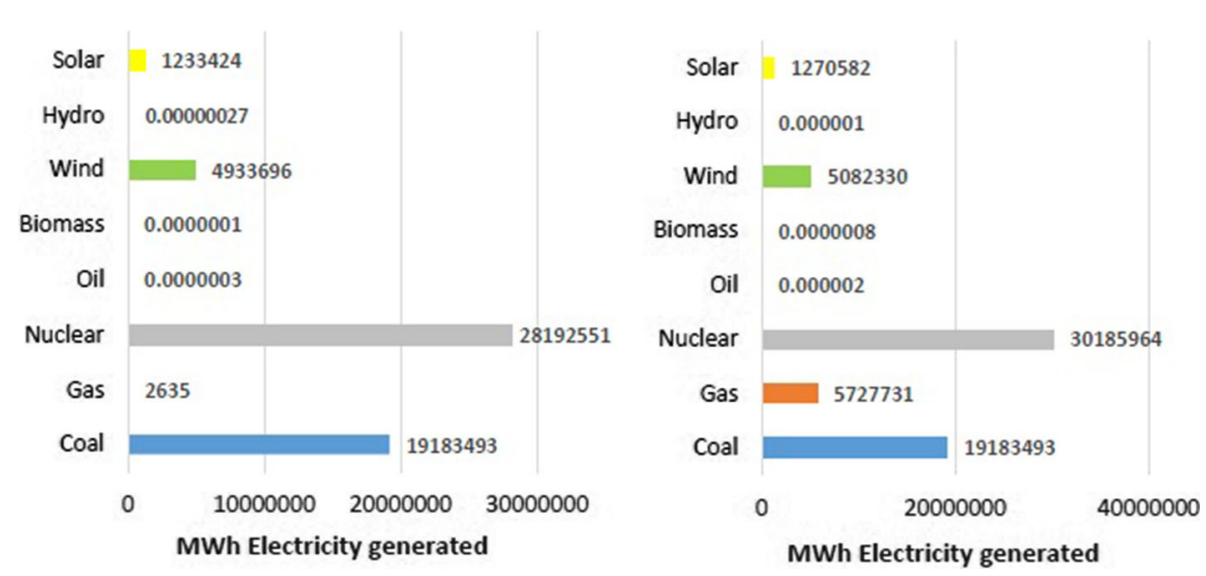

Fig. 5 Cost optimized lower and upper bounds of electricity generation

Each of the objective functions tries to optimize the electricity generation towards a different perspective. Therefore, focusing on the decomposed results of each of the solutions provided by each objective function provides a straight-forward outlook. This is particularly important for decision makers who need valuable insights about each perspective that can assist future planning.

Figure 5 shows the results of total electricity generation by each system during the first 6 months of a year from economical point of view and considering only minimization of fixed and variable costs.

Higher fixed cost for renewable resources, which results in lower installation capacity, and our second assumption lead to higher total generation by conventional systems. Among thermal power stations, nuclear is benefitted by low production cost and as a result has the highest share of electricity generation. Also among renewable resources, hydro by having the costliest variable operation and maintenance ( $£ 6 / \mathrm{MWh})$ has approximately zero share of the electricity generation.

Figure 6 shows the results occurring by minimizing imports dependence. Biomass, oil and coal have been eliminated because they are highly imported in the UK. At the same time, gas and nuclear energy are partially imported to the UK but to a lesser extent than the aforementioned resources. It is reminded that one of the system constrains requires that renewable energy does not completely take over due to its intermittency; therefore, we still have thermal power stations meeting most of the demand.

When focusing on $\mathrm{CO}_{2}$ emissions and environmental criteria the results are particularly interesting (Figs. 7, 8). With regards to $\mathrm{CO}_{2}$ emissions, as expected, alternatives with zero generation emissions such as nuclear and renewables prevailed. However, it is reminded that $\mathrm{CO}_{2}$ emissions have been assessed on a lifecycle basis; therefore, nuclear has taken the lead since it presents relatively lower levelised emissions. Moreover, for the UK standards biomass is considered to be $\mathrm{CO}_{2}$ neutral since its direct generation emissions are approximately equal to the $\mathrm{CO}_{2}$ that has been absorbed for biomass growth.

When evaluating power production alternatives against a broader set of environmental criteria a more diverse fuel mix occurs (Fig. 8). That is still however, based on nuclear and gas power generation as one of the system constraints requires a majority stake for thermal power stations. Moving from lower bound to upper bound of demand and increasing the feasible area for the problem wind is the most benefitted power source. 

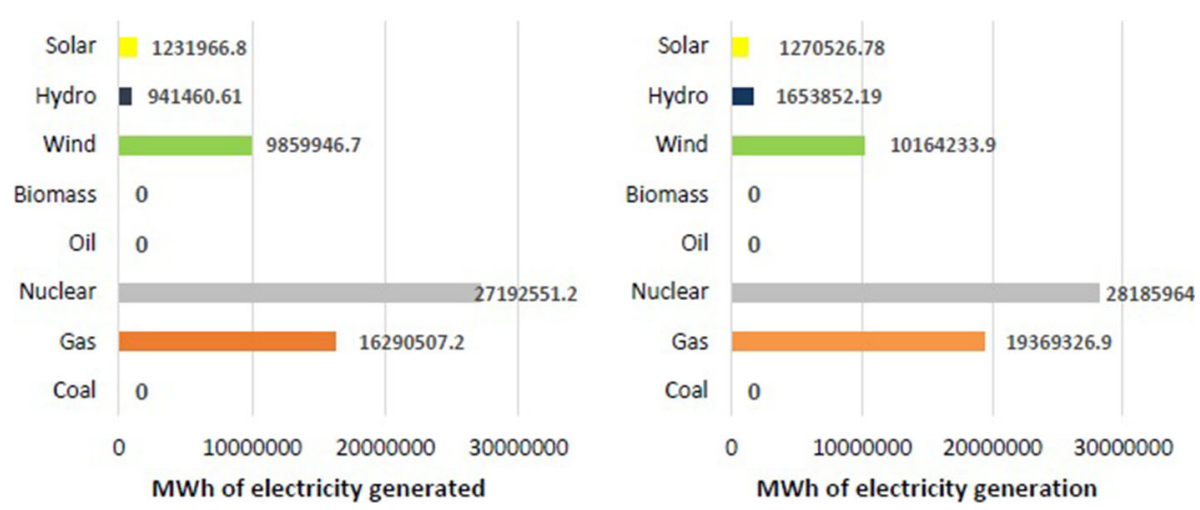

Fig. 6 Lower and upper bounds of electricity generation by minimizing imported fuel
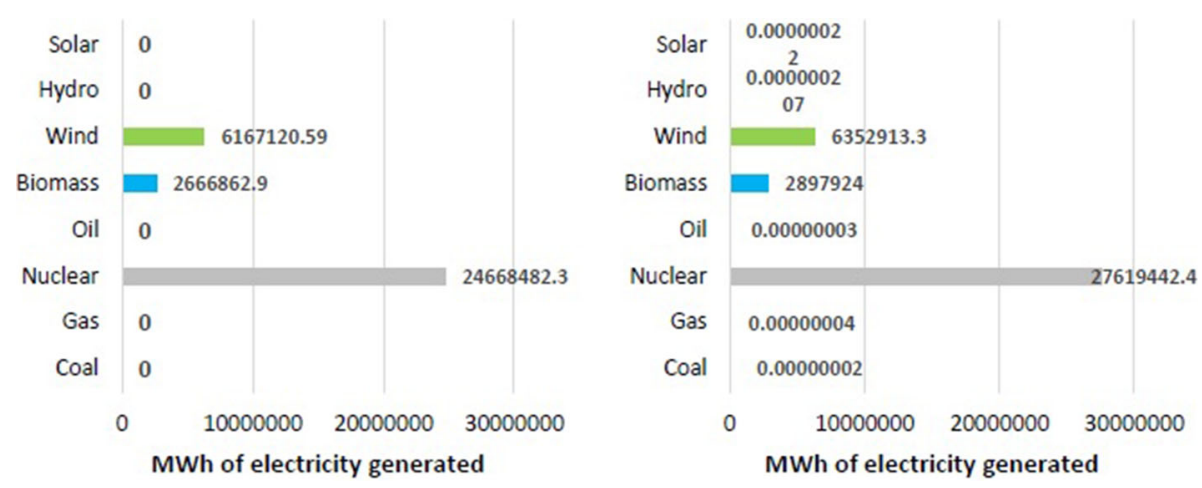

Fig. 7 Lower and upper bounds of electricity generation based on minimization of $\mathrm{CO}_{2}$ emission
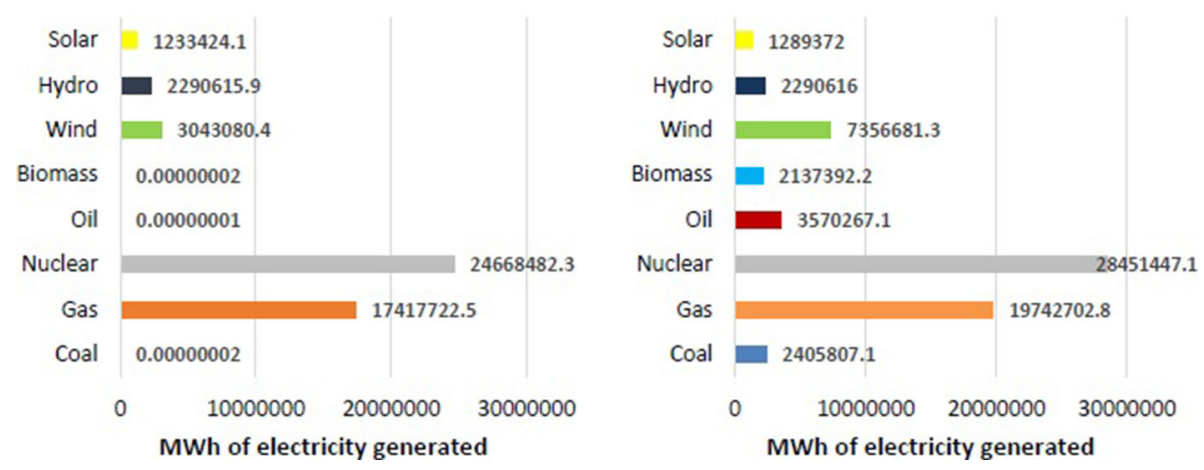

Fig. 8 Environmental optimized Lower and upper bounds of electricity generation

With the evaluation focused on social criteria (Fig. 9) the optimized fuel mix gives very high scores to nuclear and gas which are required to produce the majority of the required power. At the same time, it is clear that renewable energy sources have very little variation between their upper and lower boundaries suggesting they produce at their maximum permitted output (as occurring by the problem constraints). 

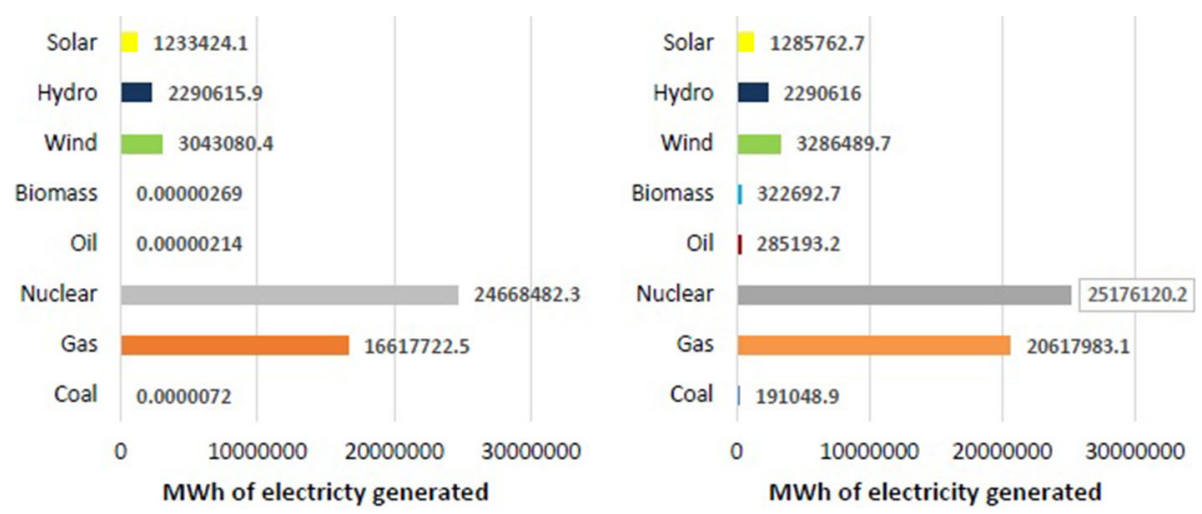

Fig. 9 Social optimized lower and upper bounds of electricity generation

\section{Discussion}

The actual fuel mix for the UK's power sector was in 2015 based on $29 \%$ gas, $21 \%$ nuclear, $22 \%$ coal, $24 \%$ by renewable including biomass, wind, hydro and solar as well as $3 \%$ by other fuels (UK Energy Statistics, 2015 \& Q4 2015). The results obtained by this research suggest that at least $28 \%$ of the total electricity supply should be produced by renewable energy systems. This is certainly limited by problem constraints such as infrastructure cost and upper limit to variable output energy sources. However, technology development in the renewable energy field is rapid and offers declining installation and maintenance costs and increased reliability. At the same time market maturity for various energy storage technologies is growing fast and brings renewables and storage hybrid solutions off their small-scale past (Zafirakis and Chalvatzis 2014). Market ready systems provide a bundle of grid services and through variable compensation schemes are attractive for private investment (Zafirakis et al. 2016). These gradually expand to non-traditional power supply systems such as for example distributed industrial facilities (Zafirakis et al. 2014)

The UK is at the forefront of these developments. Firstly, by its commitment to offshore wind energy the UK has become a world leader in installed capacity and successfully transferred its offshore engineering know-how from oil and gas to wind turbines (IRENA 2015). Secondly energy storage has been identified as one of the key innovations for the UK's technological strategy (UK Government 2013). Moreover, the UK actively promotes further development of the cross-border electricity market which enables electricity trade to improve grid stability and lower costs with existing interconnections to France, the Netherlands and Ireland and plans for further links to Norway and Denmark (OFGEM 2016). These connections will further increase the scope for more base-load renewables and have the potential to impact not only on the power market but also the emissions market (Zafirakis et al. 2015). At the same time the UK provides an interesting landscape because of its significantly development ICT infrastructure even at household level which supports a dual purpose; that of energy consumption and that of enabling smart energy management (Pothitou et al. 2016, 2017)

One clearer outcome of our research has been that coal as an electricity sector fuel is difficult to justify under any set of criteria. This echoes accurately with the UK Government's schedule for shutting down all the coal-fired power stations of the country by 2025 or even earlier (Guardian 2016). At the same time throughout our analysis, withdrawal from coal, 
leads to large-scale reliance on nuclear energy. While there are certain benefits to nuclear energy such as its capacity to deliver large-scale reliable power and its limited environmental emissions, recent developments cast doubts about the future of nuclear energy. Since, the Fukushima disaster, nuclear safety standards have been raised, and as a result led infrastructure costs to grow substantially (Boggard 2014). Furthermore, new reactor design innovations increase project completion and cost uncertainty (Riesz et al. 2016). These issues and particularly the new increased costs have not yet been clearly incorporated in the literature and therefore are not taken into account into our modelling. This explains the disparity between the completely justified reluctance of the UK Government (Financial Times 2016) to commit to new nuclear investment because of costs (The Economist 2016) and our decision making modelling essentially recommending nuclear as the best option including cost parameters.

\section{Conclusion}

Planning for electricity generation mix is a highly complex problem which confronts decision makers with multiple conflicting priorities and potentially disproportionate objectives. Established and mostly new technologies are coming with inherent uncertainties either due to their complexity or due to them being untested at scale and can affect and mislead optimization results and generation schemes. With this manuscript we put forward a new model that can support decision making for electricity fuel mix and we demonstrated it using the UK power sector as a case study. Apart from the aforementioned uncertainties, the UK presents an even more challenging case because of its recent decision to leave the EU. While this is an ongoing process, it is expected that it will stall new large-scale investment decisions which are particularly important for the energy sector. We argue that in the face of this turbulent environment our research provides the foundation of a flexible decision making tool that will be of help to policy making and assessment.

We dealt with excessive and inaccurate factors by applying two evaluation processes based on GRA to obtain the performance score of different generation systems with respect to environmental and social criteria and used the computed scores in our optimization problem to increase the share of power generations sources with the best environmental and social performance. For parameters that do not have certain or fixed values both coefficients and left hand side constraints we applied multi-objective interval grey linear programming. We found that the application of hybrid MCDM and MODM methodology is an effective approach in addressing complex and large-scale problems that include uncertainties.

Specifically for the UK we suggest an increase in all three renewable sources considered i.e. wind, solar and hydropower and significant decrease of coal and oil due to their prohibitive environmental and social impact and reliance on imports. Our results are contextualised and contrasted with the UK Governments' policies as we recommend significantly stronger support for renewable energy sources than is currently in place.

Two of the limitations of this research are inherent within our assumptions. Firstly in the fact that we have considered the UK power system as a closed ecosystem without any crossborder power trade which is not the case as the UK has international electricity connections which can have an impact on the country's power mix. Secondly, we did not consider the role of new technologies, such as energy storage, which is forthcoming in the UK both in terms of stationary storage and increasingly mobile storage in electric vehicles.

Therefore, future research should expand the scope of our present work to include the interconnectors with France, Netherlands Ireland, Denmark and Norway. Moreover, we are 
looking forward to modelling the role of energy storage in power dispatching and in optimising the use of indigenous resources in the UK or other countries. Finally, our modelling approach can be enriched with weight determining techniques such as DEMATEL and AHP in order to provide flexible planning and create a scenario development tool that will be of direct use by policy makers and take their priorities more into account.

Acknowledgements The specific study has been funded under the project TILOS (Horizon 2020 Low Carbon Energy Local/small-scale storage LCE-08-2014). This project has received funding from the European Union \& Horizon 2020 research and innovation programme under Grant Agreement No. 646529. The authors would also like to thank the project 'A cross country examination of supply chain barriers on market access for small and medium firms in India and UK' (Ref No. PM130233) funded by British Academy, UK for supporting this research.

Open Access This article is distributed under the terms of the Creative Commons Attribution 4.0 International License (http://creativecommons.org/licenses/by/4.0/), which permits unrestricted use, distribution, and reproduction in any medium, provided you give appropriate credit to the original author(s) and the source, provide a link to the Creative Commons license, and indicate if changes were made.

\section{References}

Afgan, N. H., \& Carvalho, M. G. (2002). Multi-criteria assessment of new and renewable energy power plants. Energy, 27(8), 739-755.

Afsordegan, A., Sánchez, M., Agell, N., Zahedi, S., \& Cremades, L. V. (2016). Decision making under uncertainty using a qualitative TOPSIS method for selecting sustainable energy alternatives. International Journal of Environmental Science and Technology, 13(6), 1419-1432.

Arce, M. E., Saavedra, Á., Míguez, J. L., \& Granada, E. (2015). The use of grey-based methods in multi-criteria decision analysis for the evaluation of sustainable energy systems: A review. Renewable and Sustainable Energy Reviews, 47, 924-932.

Armaroli, N., \& Balzani, V. (2011). Towards an electricity-powered world. Energy and Environmental Science, 4(9), 3193-3222.

Arnette, A., \& Zobel, C. W. (2012). An optimization model for regional renewable energy development. Renewable and Sustainable Energy Reviews, 16(7), 4606-4615.

Balat, M. (2006). Electricity from worldwide energy sources. Energy Sources, Part B: Economics, Planning and Policy, 1(4), 395-412.

Boggard, N. (2014). The cost of nuclear electricity: France after Fukushima. Energy Policy, 66, 450-461.

Büyüközkan, G., \& Güleryüz, S. (2016). An integrated DEMATEL-ANP approach for renewable energy resources selection in Turkey. International Journal of Production Economics, 182, 435-448.

Cabello, J. M., Luque, M., Miguel, F., Ruiz, A. B., \& Ruiz, F. (2014). A multiobjective interactive approach to determine the optimal electricity mix in Andalucía (Spain). Top, 22(1), 109-127.

Cai, Y., Huang, G. H., Nie, X. H., Li, Y. P., \& Tan, Q. (2007). Municipal solid waste management under uncertainty: A mixed interval parameter fuzzy-stochastic robust programming approach. Environmental Engineering Science, 24(3), 338-352.

Çelikbilek, Y., \& Tüysüz, F. (2016). An integrated grey based multi-criteria decision making approach for the evaluation of renewable energy sources. Energy, 115, 1246-1258.

Chalvatzis, K. J. (2009). Electricity generation development of Eastern Europe: A carbon technology management case study for Poland. Renewable and Sustainable Energy Reviews, 13(9), 2703-2709.

Chalvatzis, K. J., \& Rubel, K. (2015). Electricity portfolio innovation for energy security: The case of carbon constrained China. Technological Forecasting and Social Change, 100, 267-276.

Cheng, S., Chan, C. W., \& Huang, G. H. (2003). An integrated multi-criteria decision analysis and inexact mixed integer linear programming approach for solid waste management. Engineering Applications of Artificial Intelligence, 16(5), 543-554.

Conca, J. (2012). How deadly is your kilowatt? We rank the killer energy sources. Forbes. Available online at: http://www.forbes.com/sites/jamesconca/2012/06/10/energys-deathprint-a-pricealways-paid/\#2ffb6f6a49d2.

Cong, R. G. (2013). An optimization model for renewable energy generation and its application in China: A perspective of maximum utilization. Renewable and Sustainable Energy Reviews, 17, 94-103.

Data Explorer | National Grid. www2.nationalgrid.com. N.p., 2016. Web. 10 Jul. 2016. 
Deng, J. L. (1982). Grey system fundamental method. Wuhan: Huazhong University of Science and Technology.

Department of Energy and Climate Change (DECC). (2013). Electricity generation costs 2013.

Economist. (2016). Hinkley pointless. Available online at: http://www.economist.com/news/leaders/ 21703367-britain-should-cancel-its-nuclear-white-elephant-and-spend-billions-making-renewables.

Electricity Statistics - GOV.UK. Gov.uk. N.p., 2016. Web. 10 Aug. 2016.

European Environment Agency (EEA/EMEP). (2013). Air pollutant emission inventory guidebook. Available online at: http://www.eea.europa.eu/publications/emep-eea-guidebook-2013.

Evans, A., Strezov, V., \& Evans, T. J. (2009). Assessment of sustainability indicators for renewable energy technologies. Renewable and Sustainable Energy Reviews, 13(5), 1082-1088.

Fan, Y. R., \& Huang, G. H. (2012). A robust two-step method for solving interval linear programming problems within an environmental management context. Journal of Environmental Informatics, 19(1), 1-9.

Financial Times. (2016). Hinkley Point: 'I am prime minister, this is my method,' says May. Available online at: https://www.ft.com/content/6e0b3354-5580-11e6-befd-2fc0c26b3c60.

Grubb, M., Butler, L., \& Twomey, P. (2006). Diversity and security in UK electricity generation: The influence of low-carbon objectives. Energy Policy, 34, 4050-4062.

Guardian. (2016). Green conservatives call for earlier UK coal power phase-out. Available online at: https:// www.theguardian.com/environment/2016/jun/07/uk-should-shut-down-all-coal-power-plants-twoyears-before-2025-pledge.

Han, Y., Huang, Y. F., Wang, G. Q., \& Maqsood, I. (2011). A multi-objective linear programming model with interval parameters for water resources allocation in Dalian city. Water Resources Management, 25(2), 449-463.

Hladı, M. (2013). Weak and strong solvability of interval linear systems of equations and inequalities. Linear Algebra and Its Applications, 438(11), 4156-4165.

Hofmann, J., Guan, D., Chalvatzis, K., \& Huo, H. (2016). Assessment of electrical vehicles as a successful driver for reducing $\mathrm{CO}_{2}$ emissions in China. Applied Energy, 184, 995-1003.

Huang, G., Baetz, B. W., \& Patry, G. G. (1992). A grey linear programming approach for municipal solid waste management planning under uncertainty. Civil Engineering Systems, 9(4), 319-335.

Huang, G. H., Baetz, B. W., \& Patry, G. G. (1995). Grey integer programming: an application to waste management planning under uncertainty. European Journal of Operational Research, 83, 594-620.

International Renewable ENergy Agency (IRENA). (2015). 30 Years of Policies for Wind Energy: Lessons from United Kingdom. Available online at: https://www.irena.org/DocumentDownloads/Publications/ GWEC_UK.pdf.

Joint Research Centre (JRC). (2013). Assessment of the European potential for pumped hydropower energy storage: A GIS-based assessment of pumped hydropower storage potential by Marcos Gimeno-Gutiérrez and Roberto Lacal-Arántegui. Report EUR 25940 EN.

Kabak, M., \& Dağdeviren, M. (2014). Prioritization of renewable energy sources for Turkey by using a hybrid MCDM methodology. Energy Conversion and Management, 79, 25-33.

Kalkuhl, M., Edenhofer, O., \& Lessmann, K. (2012). Learning or lock-in: Optimal technology policies to support mitigation. Resource and Energy Economics, 34(1), 1-23.

Kaldellis, J. K., Spyropoulos, G. C., Chalvatzis, K. J., \& Paliatsos, A. G. (2006). Minimum SO 2 electricity sector production using the most environmental friendly power stations in Greece. Fresenius Environmental Bulletin, 15(11), 1394-1399.

Kaya, I., \& Kahraman, C. (2009). Fuzzy robust process capability indices for risk assessment of air pollution. Stochastic Environmental Research and Risk Assessment, 23(4), 529-541.

Koroneos, C., Michailidis, M., \& Moussiopoulos, N. (2004). Multi-objective optimization in energy systems: the case study of Lesvos Island. Greece. Renewable and Sustainable Energy Reviews, 8(1), 91-100.

Lilliestam, J., \& Hanger, S. (2016). Shades of green: Centralisation, decentralisation and controversy among European renewable electricity visions. Energy Research \& Social Science, 17, $20-29$.

Linares, P., \& Romero, C. J. (2000). A multiple criteria decision making approach for electricity planning in Spain: Economic versus environmental objectives. Journal of the Operational Research Society, 51(6), 736-743.

Liu, G., Baniyounes, A. M., Rasul, M. G., Amanullah, M. T. O., \& Khan, M. M. K. (2013). General sustainability indicator of renewable energy system based on grey relational analysis. International Journal of Energy Research, 37(14), 1928-1936.

Macknick, J., Newmark, R., Heath, G., \& Hallett, K. C. (2012). Operational water consumption and withdrawal factors for electricity generating technologies: A review of existing literature. Environmental Research Letters, 7(4), 045802.

Manzardo, A., Ren, J., Mazzi, A., \& Scipioni, A. (2012). A grey-based group decision-making methodology for the selection of hydrogen technologies in life cycle sustainability perspective. International Journal of Hydrogen Energy, 37(23), 17663-17670. 
Maxim, A. (2014). Sustainability assessment of electricity generation technologies using weighted multicriteria decision analysis. Energy Policy, 65, 284-297.

Newbery, D. (2016). Missing money and missing markets: Reliability, capacity auctions and interconnectors. Energy Policy, 94, 401-410.

Perera, A. T. D., Attalage, R. A., Perera, K. K. C. K., \& Dassanayake, V. P. C. (2013). A hybrid tool to combine multi-objective optimization and multi-criterion decision making in designing standalone hybrid energy systems. Applied Energy, 107, 412-425.

Pothitou, M., Hanna, R. F., \& Chalvatzis, K. J. (2016). Environmental knowledge, pro-environmental behaviour and energy savings in households: An empirical study. Applied Energy, 184, 1217-1229.

Pothitou, M., Hanna, R. F., \& Chalvatzis, K. J. (2017). ICT Entertainment appliances' impact on domestic electricity consumption. Renewable and Sustainable Energy Reviews, 69, 843-853.

Promjiraprawat, K., \& Limmeechokchai, B. (2013). Multi-objective and multi-criteria optimization for power generation expansion planning with $\mathrm{CO}_{2}$ mitigation in Thailand. Songklanakarin Journal of Science \& Technology, 35(3).

Purwanto, W. W., Pratama, Y. W., Nugroho, Y. S., Hertono, G. F., Hartono, D., \& Tezuka, T. (2015). Multi-objective optimization model for sustainable Indonesian electricity system: Analysis of economic, environment, and adequacy of energy sources. Renewable Energy, 81, 308-318.

Ren, J., Dong, L., Sun, L., Goodsite, M. E., Tan, S., \& Dong, L. (2015). Life cycle cost optimization of biofuel supply chains under uncertainties based on interval linear programming. Bioresource Technology, 187, 6-13.

Riesz, J., Sotiriadis, C., Vithayasrichareon, P., \& Gilmore. J. (2016). Quantifying key uncertainties in the costs of nuclear power. Working Paper. Available online at: http://nuclearrc.sa.gov.au/app/uploads/2016/02/ Dr-Jenny-Riesz-20-10-2015.pdf.

Sadeghi, A., Larimian, T., \& Molabashi, A. (2012). Evaluation of renewable energy sources for generating electricity in province of Yazd: A fuzzy MCDM approach. Procedia-Social and Behavioral Sciences, 62, 1095-1099.

Sackman, H. (1974). Delphi assessment: Expert opinion, forecasting, and group process (No. RAND-R-1283PR). RAND CORP SANTA MONICA CA.

Santoyo-Castelazo, E., \& Azapagic, A. (2014). Sustainability assessment of energy systems: Integrating environmental, economic and social aspects. Journal of Cleaner Production, 80, 119-138.

Sarucan, A., Baysal, M. E., Kahraman, C. \& Engin, O. (2011). A hierarchy grey relational analysis for selecting the renewable electricity generation technologies. In Proceedings of the world congress on engineering (Vol. 2, pp. 1149-1154).

Şengül, Ü., Eren, M., Shiraz, S. E., Gezder, V., \& Şengül, A. B. (2015). Fuzzy TOPSIS method for ranking renewable energy supply systems in Turkey. Renewable Energy, 75, 617-625.

Sioshansi, R. (2012). OR forum-Modeling the impacts of electricity tariffs on plug-in hybrid electric vehicle charging, costs, and emissions. Operations Research, 60(3), 506-516.

Sithole, H., Cockerill, T. T., Hughes, K. J., Ingham, D. B., Ma, L., Porter, R. T. J., et al. (2016). Developing an optimal electricity generation mix for the UK 2050 future. Energy, 100, 363-373.

Statistical Press Release; UK Energy Statistics, 2015 \& Q4 2015. Available online at: https://www.gov.uk/ government/uploads/system/uploads/attachment_data/file/513244/Press_Notice_March_2016.pdf.

Stein, E. W. (2013). A comprehensive multi-criteria model to rank electric energy production technologies. Renewable and Sustainable Energy Reviews, 22, 640-654.

Stirling, A. (1994). Diversity and ignorance in electricity supply investment: Addressing the solution rather than the problem. Energy Policy, 22(3), 195-216.

Strbac, G. (2008). Demand side management: Benefits and challenges. Energy Policy, 36(12), 4419-4426.

Streimikiene, D., Balezentis, T., Krisciukaitienė, I., \& Balezentis, A. (2012). Prioritizing sustainable electricity production technologies: MCDM approach. Renewable and Sustainable Energy Reviews, 16(5), 33023311.

Tasri, Adek, \& Susilawati, Anita. (2014). Selection among renewable energy alternatives based on a fuzzy analytic hierarchy process in Indonesia. Sustainable Energy Technologies and Assessments, 7, 34-44.

UK Government. (2013). Industrial strategy: Eight great technologies. Available online at: https://www. gov.uk/government/uploads/system/uploads/attachment_data/file/249255/eight_great_technologies_ overall_infographic.pdf.

Unsihuay-Vila, C., Marangon-Lima, J. W., De Souza, A. Z., \& Perez-Arriaga, I. J. (2011). Multistage expansion planning of generation and interconnections with sustainable energy development criteria: A multiobjective model. International Journal of Electrical Power \& Energy Systems, 33(2), 258-270.

Wang, J. J., Jing, Y. Y., Zhang, C. F., \& Zhao, J. H. (2009). Review on multi-criteria decision analysis aid in sustainable energy decision-making. Renewable and Sustainable Energy Reviews, 13(9), 2263-2278. 
Warren, P. (2014). A review of demand-side management policy in the UK. Renewable and Sustainable Energy Reviews, 29, 941-951.

Xu, G., Yang, Y. P., Lu, S. Y., Li, L., \& Song, X. (2011). Comprehensive evaluation of coal-fired power plants based on grey relational analysis and analytic hierarchy process. Energy Policy, 39(5), 2343-2351.

Zafirakis, D., \& Chalvatzis, K. J. (2014). Wind energy and natural gas-based energy storage to promote energy security and lower emissions in island regions. Fuel, 115, 203-219.

Zafirakis, D., Elmasides, C., Sauer, D. U., Leuthold, M., Merei, G., Kaldellis, J. K., et al. (2014). The multiple role of energy storage in the industrial sector: Evidence from a Greek industrial facility. Energy Procedia, $46,178-185$.

Zafirakis, D., Chalvatzis, K. J., Baiocchi, G., \& Daskalakis, G. (2016). The value of arbitrage for energy storage: Evidence from European electricity markets. Applied Energy, 184, 971-986.

Zafirakis, D., Chalvatzis, K. J., \& Baiocchi, G. (2015). Embodied $\mathrm{CO}_{2}$ emissions and cross-border electricity trade in Europe: Rebalancing burden sharing with energy storage. Applied Energy, 143, 283-300.

Zafirakis, D., Chalvatzis, K., \& Kaldellis, J. K. (2013). Socially just support mechanisms for the promotion of renewable energy sources in Greece. Renewable and Sustainable Energy Reviews, 21, 478-493. 